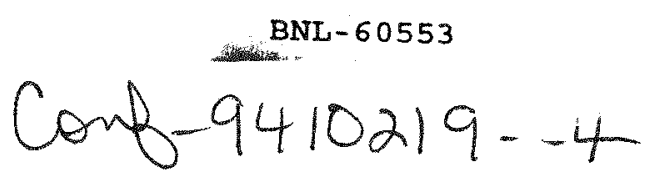

\title{
Instrumentation for On-line Mountain Range Displays*
}

\author{
W.K. van Asselt and L.A. Ahrens \\ AGS Department, Brookhaven National Laboratory \\ Upton, Long Island, New York 11973
}

\begin{abstract}
A method to obtain and process 'mountain range' displays of beam signals is described. A custom-made trigger generator and a digital oscilloscope are used for the data acquisition and the graphical interface package LabVIEW is used to process the data. High resolution displays of wall monitor signals updating every AGS cycle have proven very powerful as a beam diagnostic.
\end{abstract}

\section{INTRODUCTION}

The development of the longitudinal structure of a bunch can be obtained by observing beam pickup signals, typically from a wall monitor, from a given bunch at regularly spaced intervals. This is because the longitudinal structure evolves relatively slow, since the synchrotron frequency is in general small compared to the revolution frequency. By overlaying a series of beam traces all starting synchronized to the accelerating rf but with slight vertical offsets for successive traces some aspects of the motion become very easy to visualize. This is the mountain-range display. The use of these displays for beam observations in the time domain has been very common in the accelerator community using analog storage oscilloscopes and the appropriate trigger and ramp generators. This paper describes this same basic technique, customized for data acquisition with a digital oscilloscope. There are three main ingredients composing the present method: a trigger generator chassis, sequential digital data acquisition and transfer and display of the data at a host computer. These ingredients will be described, followed by a discussion of the performance of the system.

\section{THE TRIGGER GENERATOR}

When acquiring data with an analog oscilloscope, the trigger sequence to the scope completely defines the pattern observed. Although capturing the data digitally opens the possibility for further processing, the triggers give an essential reference to the rf buckets in the machine. Further, selective triggering allows a preprocessing which reduces the time requirements before the data can be displayed. It has been considered critical in the present application to be able to

*Work performed under the auspices of the U.S. Department of Energy. 
present the display in real time - within one accelerator cycle. For these reasons a trigger generator chassis similar to that used in analog mountain-range displays is still necessary. This chassis generates a sequence of triggers, which are fundamentally synchronized to the rf accelerating voltage. A representation of this voltage, usually a "vector sum" signal, is converted from a sinusoidal waveform to an rf pulse train. This train is counted down by the harmonic number - the ratio of the rf frequency to the revolution frequency - to generate the basic train for the acquisition triggers. A reset pulse for the harmonic count down circuit allows this train to be locked to a particular bunch. Finally this train is gated to allow a pulse only after a user specified time interval. This last sets the time scale of interest. An additional option in the trigger scheme allows an explicit violation of the synchronization to a particular bunch. Everything applies as before except every trigger slips by one rf cycle relative to the previous one. This allows a quick comparison of the shapes of all the bunches in the machine in a single mountain-range display.

\section{SEQUENTIAL DATA ACQUISITION}

Digital oscilloscopes are normally slow with respect to their rearming time. The sequence trigger mode, available on some models, is being used for this application. In this mode the acquisition memory of the oscilloscope is divided in a number of segments and each segment is filled at each subsequent trigger at the sampling rate of the oscilloscope. In this way rearming rates over $10 \mathrm{kHz}$ have been obtained. This does not provide for turn-by-turn observation of beam bunches, but standard single shot data acquisition will allow for these observations within the limitations of the available acquisition memory.

\section{DATA TRANSFER AND DISPLAY}

The oscilloscope is controlled from application codes or Virtual Instruments (VIs), written by the graphical programming language LabVIEW, which runs on a SUN-sparc station. This workstation is connected by ethernet to the AGS Distributed Controls System (AGSDCS). Data from the oscilloscope are transferred from the GPIB port through a GPIB-ENET controller. A typical VI will arm the oscilloscope to acquire a waveform, wait for a service request signaling that data acquisition is completed, transfer the sequenced waveform to the workstation and display it. This sequence being built in a while loop, which repeats itself until being stopped by the user.

\section{DISCUSSION}

The longitudinal structure of the beam at the AGS is both rich and critical, especially in the effort to accelerate very high proton intensities. The Booster synchrotron batch fills the AGS ring over four Booster cycles in $400 \mathrm{~ms}$. The 


\section{DISCLAIMER}

This report was prepared as an account of work sponsored by an agency of the United States Government. Neither the United States Government nor any agency Thereof, nor any of their employees, makes any warranty, express or implied, or assumes any legal liability or responsibility for the accuracy, completeness, or usefulness of any information, apparatus, product, or process disclosed, or represents that its use would not infringe privately owned rights. Reference herein to any specific commercial product, process, or service by trade name, trademark, manufacturer, or otherwise does not necessarily constitute or imply its endorsement, recommendation, or favoring by the United States Government or any agency thereof. The views and opinions of authors expressed herein do not necessarily state or reflect those of the United States Government or any agency thereof. 


\section{DISCLAIMER}

Portions of this document may be illegible in electronic image products. Images are produced from the best available original document. 


\section{DISCLAIMER}

Portions of this document may be illegible in electronic image products. Images are produced from the best available original document. 
bunches are "flattened" longitudinally twice during the acceleration cycle. The acceleration of the beam through transition, lately with a "jump" system, is also sensitive in the longitudinal space. Finally the slow extraction of the beam is sensitive to the longitudinal structure of the beam.

Figure 1 shows a typical display obtained with the mountain-range system, in this case an overview of the injection process of beam from the Booster into the AGS during high intensity proton operation. Higher traces come later in time in the graph; the trace separation is $6 \mathrm{~ms}$. The full horizontal scale is $3.4 \mu \mathrm{s}$, slightly more then one revolution of the beam in the AGS, which operated at the eighth harmonic. The AGS is seen to be filled by the four consecutive batches of the Booster operating at a $7.5 \mathrm{~Hz}$ repetition frequency. With the AGS executing one cycle every 3 second displays like Figure 1, involving the acquisition of 16 kbytes of data, can be obtained on a cycle by cycle basis. The limiting factor for the information flow in our configuration is the rate at which our (first generation) $1 \mathrm{Gs} / \mathrm{s}$ oscilloscope transfers the data through the GPIB bus. More recent models digital oscilloscopes have been tested and have shown data transfer rates of over 100 kbytes per second.

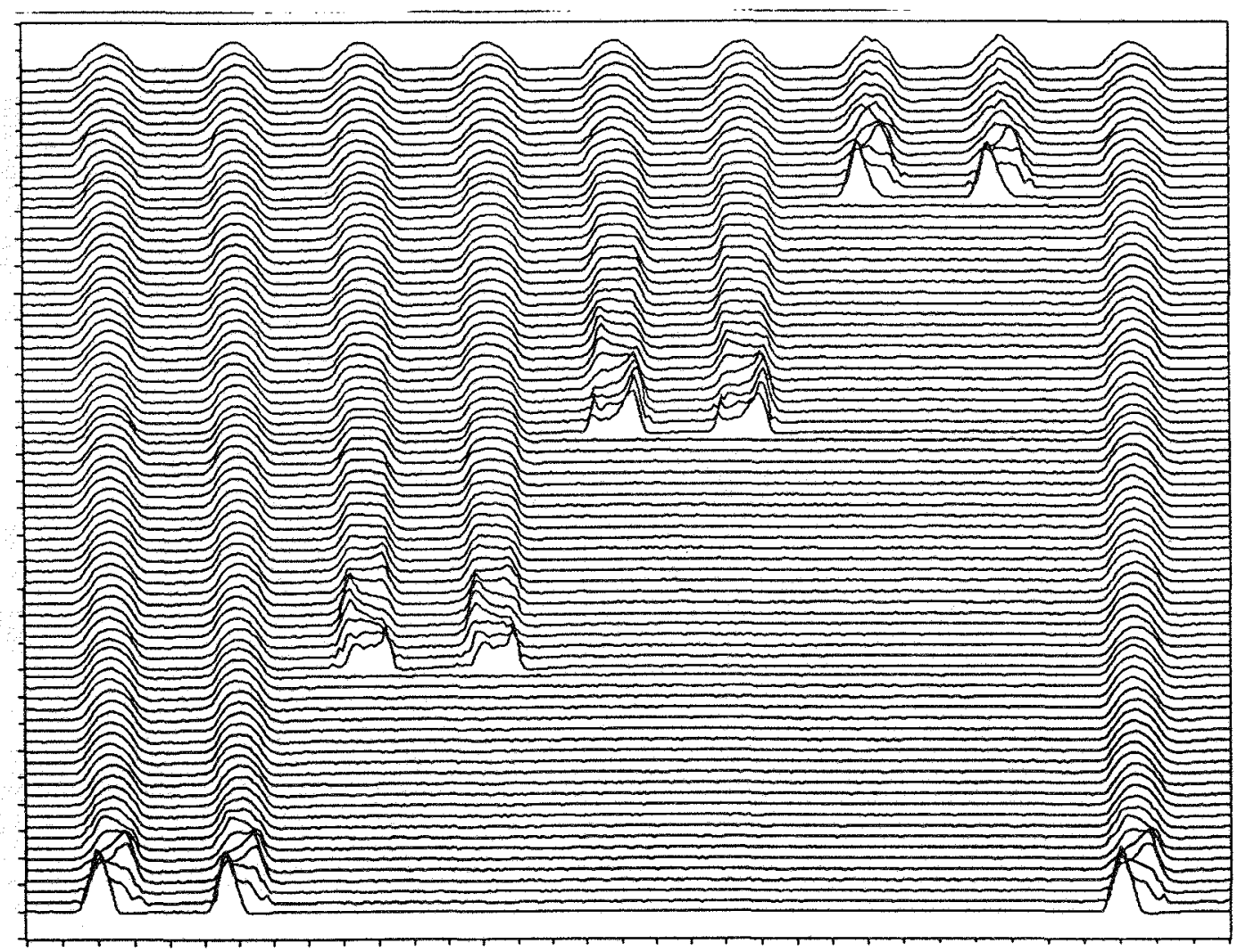

Figure 1. Overview of the injection process from the Booster into the AGS during high intensity proton operation. 
Figure 2 shows details of the injection of the first batch of protons from the Booster into the AGS. The display at left has a trace every $\mathrm{ms}$, while at right the trace separation is $100 \mu \mathrm{s}$. The full horizontal scale for both displays is 750 ns. The bunches are injected mismatched with respect to the rf buckets and since the phase loop is turned off they execute coherent synchrotron oscillations. These oscillations are flattened by the very high frequency (VHF) cavity in such a way that a controlled longitudinal dilution of the bunches results. This process is repeated for every consecutive transfer.
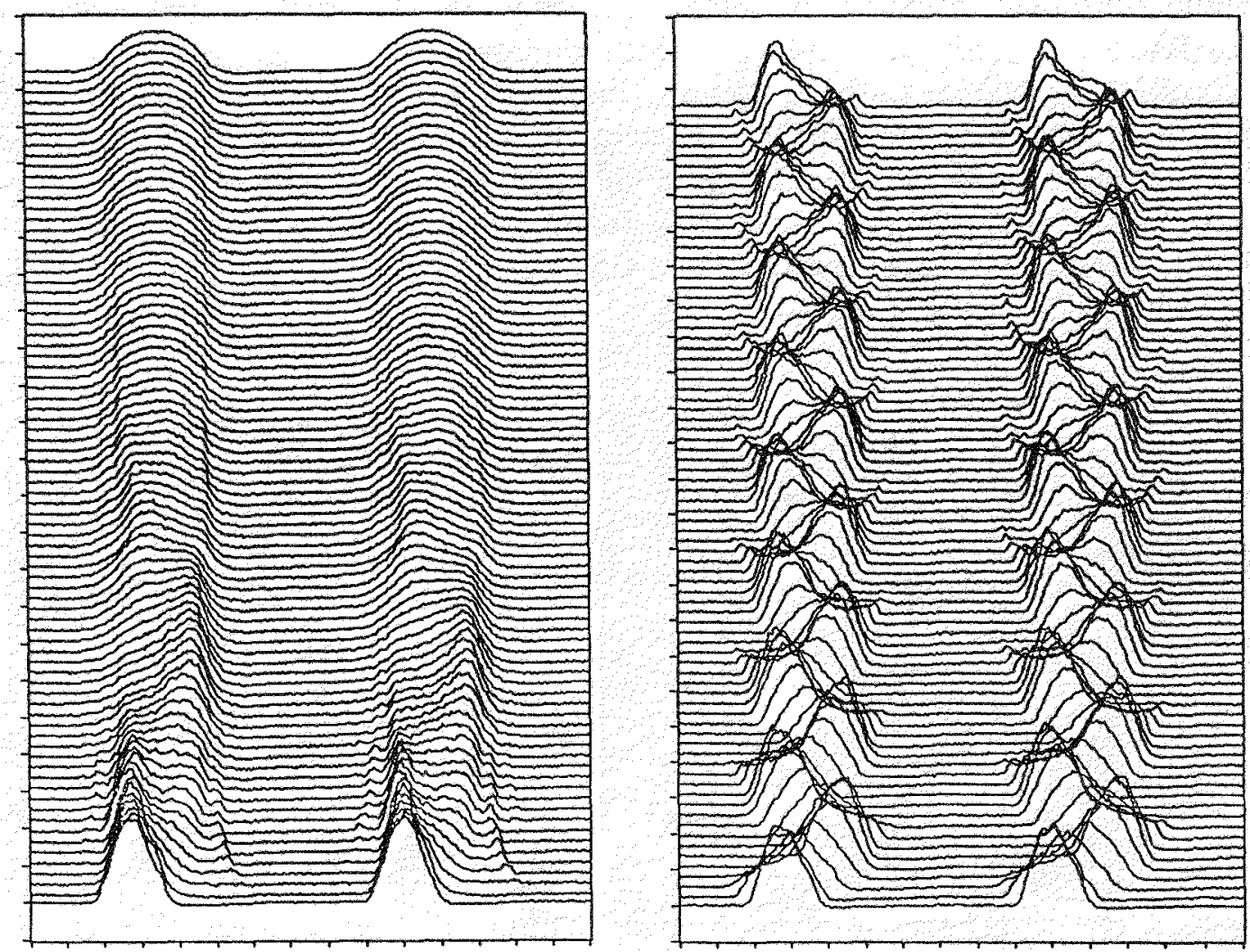

Figure 2. Displays showing the controlled longitudinal dilution of the bunches in the AGS.

An example of a turn-by-turn display is shown in Figure 3. In this case, 50 kbytes of data have been acquired and the maintain-range display has been constructed in LabVIEW. The figure shows ion beam bunches in the Booster accelerated on the 9th harmonic, which are rotating in 3rd harmonic buckets (3 bunches per bucket). This method improves the transfer efficiency from the Booster to the AGS. For this figure, the extraction from the Booster was turned off. The bunches are not lined up through rf synchronization anymore, the ability of lining up the bunches being determined by the sampling frequency, $100 \mathrm{MHz}$ in Figure 3. 


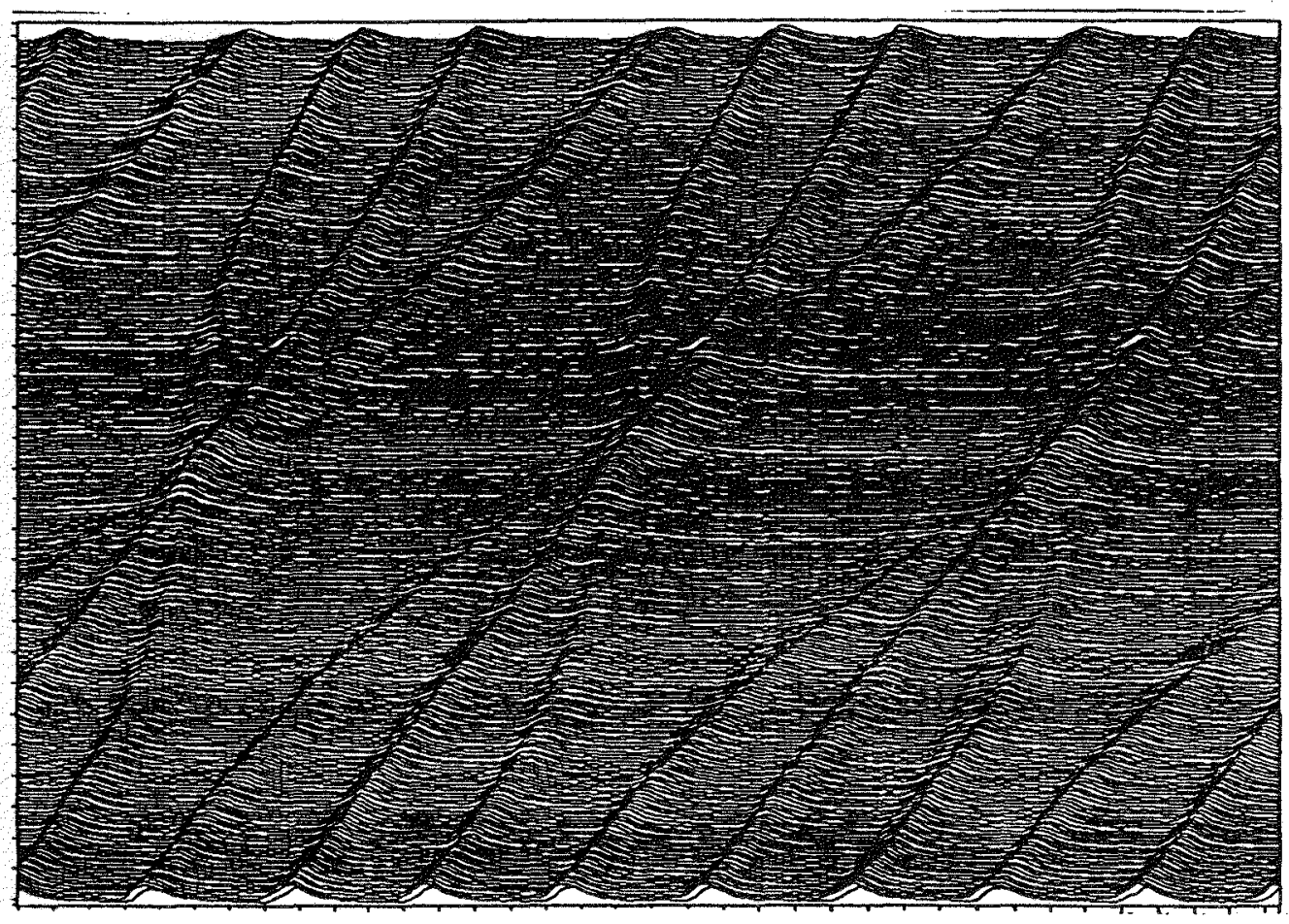

Figure 3. Turn-by-turn display of Gold ions in the Booster.

The advantage of the present method with respect to the acquisition with analog storage scopes are manifold. The much larger display of a workstation allows much more information to be presented. This method eliminates the need for "persistence" adjustments, which are so tedious necessary when adjusting the sweep speeds with analog storage scopes. The whole CRT of the workstation can be used for the display of the data, which means that considerably more details of the development of the longitudinal structure of the beam can be displayed usefully. Also, the VIs that run the mountain-range displays can be started from all workstations of the AGSDCS, allowing beam observations at remote locations. This is in contrast with the analog system, where beam observations are tied to the location where the high bandwidth signals, typically from a resistive wall monitor, are available: For the AGS, with rf frequencies in the 1-5 $\mathrm{MHz}$ range, the horizontal resolution of 1 ns matches well with the bandwidth of the wall monitor.

This method distinguishes itself from approaches where one digitizes beam signals continuously, writes Megabytes of data to disk and reconstructs beam spectra afterwards. These methods do not allow for the on-line beam observations, which the present method does, by acquiring only those data, which are deemed to be relevant. 


\section{DISCLAMER}

This report was prepared as an account of work sponsored by an agency of the United States Government. Neither the United States Government nor any agency thereof, nor any of their employees, makes any warranty, express or implied, or assumes any legal liability or responsibility for the accuracy, completeness, or usefulness of any information, apparatus, product, or process disclosed, or represents that its use would not infringe privately owned rights. Reference herein to any specific commercial product, process, or service by trade name, trademark, manufacturer, or otherwise does not necessarily constitute or imply its endorsement, recommendation, or favoring by the United States Government or any agency thereof. The views and opinions of authors expressed herein do not necessarily state or reflect those of the United States Government or any agency thereof. 